\title{
Fatigue life prediction for bearing steel with respect to inclusion induced fracture in rotating bending
}

\author{
Noriyasu Oguma ${ }^{1}$ and Tatsuo Sakai ${ }^{2}$ \\ 1. R\&D Center, Koyo Seiko Co., Ltd., Kashiwara, Japan \\ 2. Faculty of Science and Engineering, Ritsumeikan University, Kusatsu, Japan
}

\begin{abstract}
Rotating bending fatigue tests were carried out and typical factors to govern the fatigue life were experimentally examined in the long life region. Fracture mode in the long life region was an interior inclusion induced fracture with a fish-eye. At the center of the fish-eye, a non-metallic inclusion was necessarily observed, and a fine granular area (FGA) was also necessarily observed in the vicinity around the inclusion on the fracture surface. It was found that the fatigue lives were related to following three factors; (1) the stress amplitude at the inclusion, (2) the inclusion size, and (3) the FGA size. These factors can be connected to the parameters in the formula of Paris' law. Based on this aspect, the fatigue life of this steel in the above fracture mode was formulated from a viewpoint of fracture mechanics. Thus, it was found that the period forming the FGA occupied more than $90 \%$ of the total fatigue life. It was another finding that the effective factor to expand the fatigue life was smallness of the inclusion size.
\end{abstract}

Key words: Long life fatigue, Inclusion, Bearing Steel, Rotating bending, Fine granular area, Fracture mechanics

\section{INTRODUCTION}

Recently, the long life and high reliability are intensively required to machines and structures. Especially, it is demanded to clarify the fatigue property of structural steels during the long sequence of cyclic loading. Since bearing steel of SUJ2 is such a structural steel, it is important to clarify the fatigue property in the long life region of this steel. It is well known that high strength steels such a bearing steel have a significant fatigue behavior such that $S-N$ curve tends to come down again in the long life region of $N>10^{7}$ [1-8].

In this study, cantilever-type rotating bending fatigue tests were carried out for high carbon chromium bearing steel, and mechanism of interior inclusion induced fracture in the long life region was discussed from viewpoints of fractography and fracture mechanics.

\section{SPECIMEN AND EXPERIMENTAL PROCEDURE}

\subsection{Specimen}

Material used in this study is a high carbon chromium bearing steel (JIS SUJ2). Chemical composition of this steel is shown in Table 1. Specimens were machined into the shape and dimensions as shown in Fig.1. They were first cut into the diameter a little larger than the final dimension. After which these specimens were quenched $\left(835^{\circ} \mathrm{C} \mathrm{x} 40 \mathrm{~min}+\right.$ Oil quenching $)$ and tempered $\left(180^{\circ} \mathrm{C} \mathrm{x}\right.$ $120 \mathrm{~min}+$ Air cooling). Finally, they were finished into the final dimensions by a grinder. Microstructure of this material is the tempered martensite. Hardness distribution over the cross section of this material was almost flat and the average value is given as $\mathrm{HV}=730$.

\subsection{Fatigue tests}

Fatigue tests were performed by means of a multi-spindle testing machine [9] in the ordinary room atmosphere without any control of the temperature and humidity. The rotating speed of specimen was $3150 \mathrm{~min}^{-1}$ and the number of stress cycles to failure for each specimen was counted accurately by photo-sensor mounted on each specimen head. Fatigue tests were conducted at the respective stress levels giving the initial stress amplitude of $\sigma_{a}=1700 \mathrm{MPa}$ and stress decrement of $\triangle \sigma=100 \mathrm{MPa}$.

\section{EXPERIMENTAL RESULTS}

\section{1. $S-N$ characteristics}

Fatigue test data of SUJ2 were plotted as an $S-N$ diagram in Fig.2. In order to verify the crack initiation sites, the fracture surface of every failed specimen was observed by an SEM. It is found that the crack initiation sites were clearly classified into two different modes of

Table 1. Chemical composition (mass\%).

\begin{tabular}{c|c|c|c|c|c}
\hline $\mathrm{C}$ & $\mathrm{Si}$ & $\mathrm{Mn}$ & $\mathrm{Cr}$ & $\mathrm{Ti}$ & $\mathrm{O}$ \\
\hline 0.98 & 0.23 & 0.32 & 1.43 & 0.0012 & $8 \mathrm{ppm}$ \\
\hline
\end{tabular}

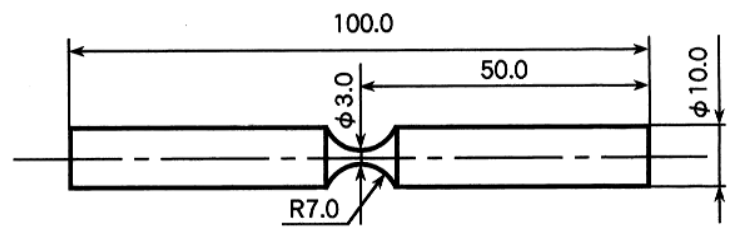

Fig. 1. Shape and dimensions of specimen. 


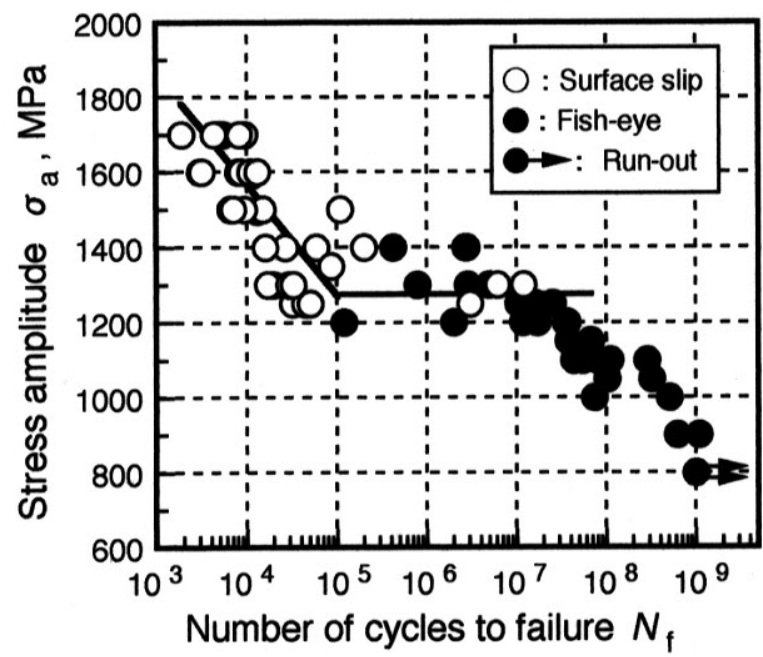

Fig.2. Duplex $S-N$ curves of SUJ2.

surface induced fracture and interior inclusion induced fracture with a fish-eye. In Fig.2, fatigue test data in the former mode were plotted by open marks of $\bigcirc$, whereas the fatigue data in the later mode were plotted by solid marks of , respectively. It is found that $S$ - $N$ curve tends to come down again in the long life region of $N>10^{7}$. Thus, the complicated $S-N$ property for this steel in the long life region can be well interpreted as the "Duplex $S-N$ property" consisting of $S-N$ curves for the respective fracture mode.
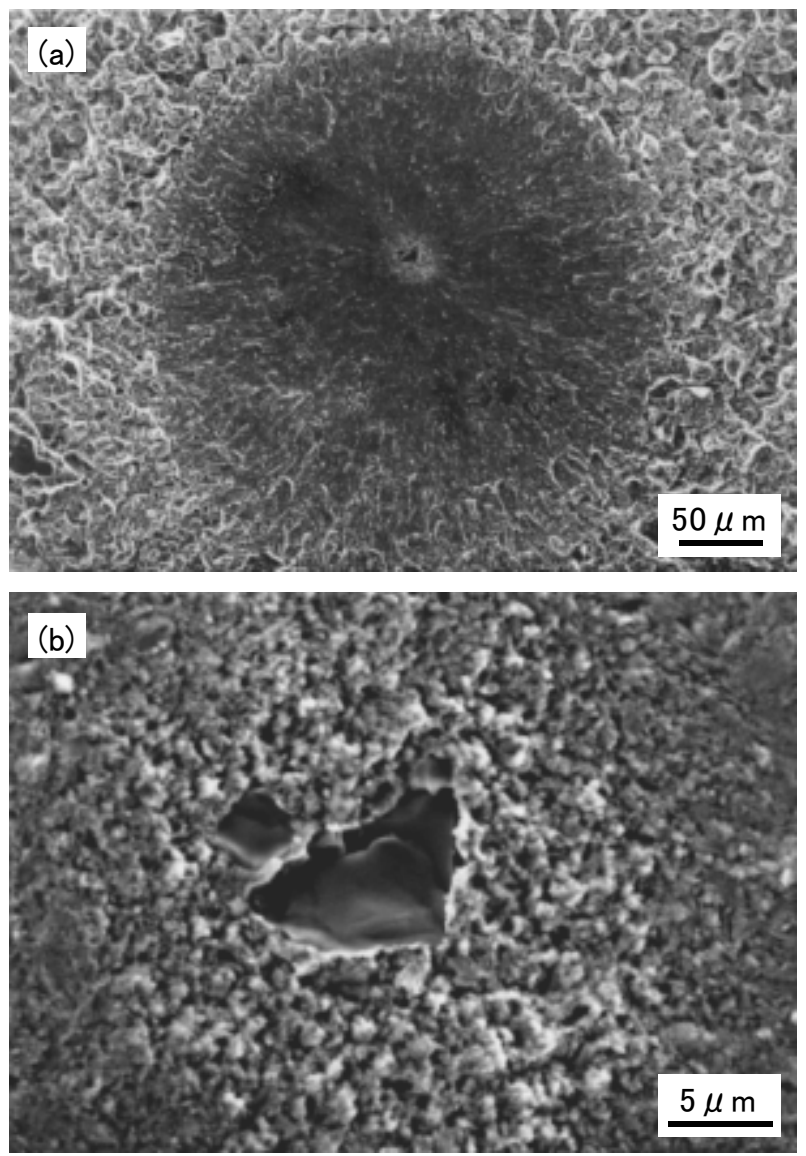

Fig.3. SEM observations at fish-eye of fracture surface.

\subsection{Fracture surface with fish-eye}

Figure 3 is an example of SEM observations at a fish-eye on the fracture surface in the long life region $\left(\sigma_{\mathrm{a}}\right.$ $=1100 \mathrm{MPa}, N_{\mathrm{f}}=2.85 \times 10^{8}$ ). A non-metallic inclusion was observed at center of the fish-eye. The central portion was again observed at high magnification and its SEM image was shown in Fig.3(b). These photographs show that the fatigue crack takes place around the inclusion in the subsurface and it propagates gradually keeping the penny shape until it reaches the specimen surface.

In the next place, high-magnification photograph around the inclusion in Fig.3(b) indicates that a rough surface area was formed in the vicinity around the inclusion. A fractgraphic feature of this area was clearly different from the outer portion of this area. Similar pattern was observed for the fracture surface with a fish-eye in every specimen. Above rough surface area in the vicinity around the inclusion was again observed in more high magnification and the photographs thus obtained were shown in Fig.4, where top and bottom ones provide a pair of matching fracture surfaces of the same position. From the stereo-photographs observation, it was found that the bright portions in Fig.4 had convex shape, whereas the dark portions had concave shape. It was another finding
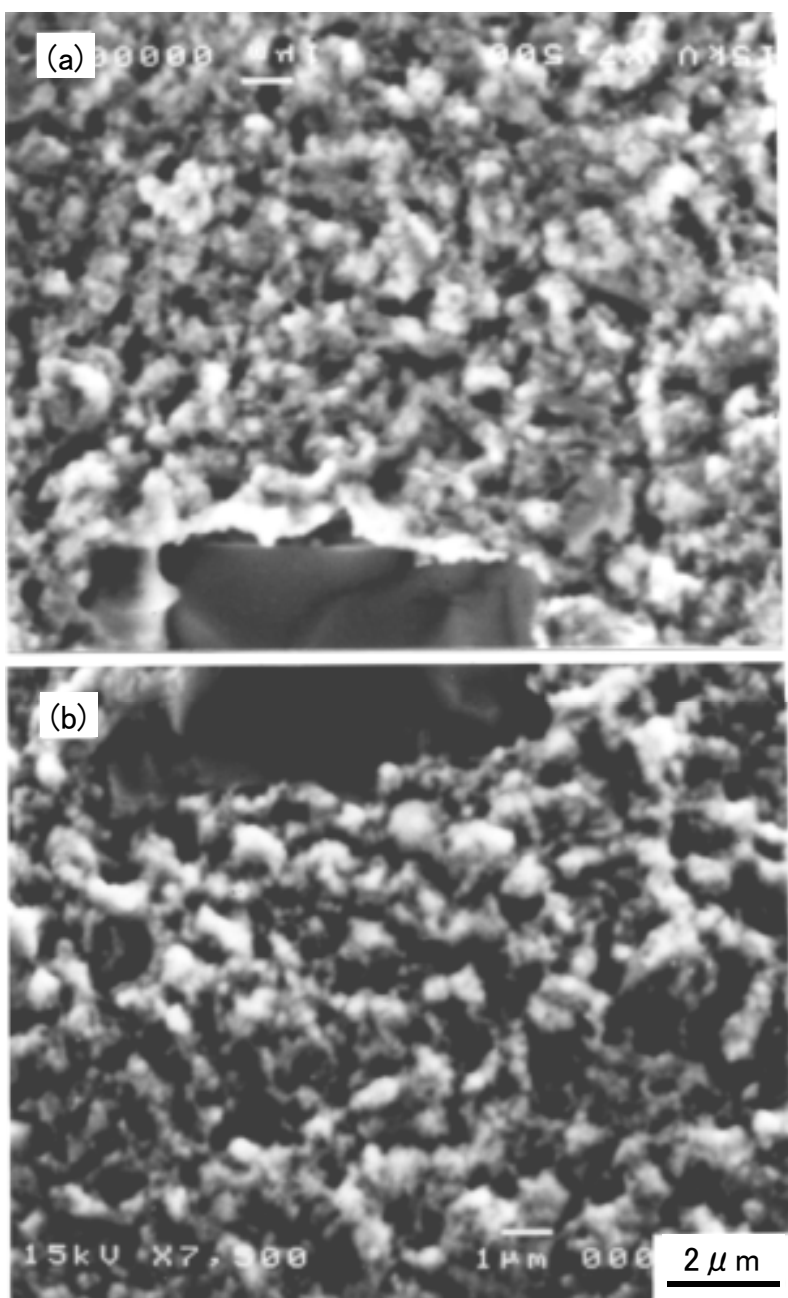

Fig.4. Matching photograph in the vicinity around the inclusion on the fracture surface. 
that the bright portion in one side was corresponding to the dark portion in the other side. So, it seems that the rough surface area looks fine granular feature. This characteristic area is hereafter so-called fine granular area (FGA) in this report.

\section{FRACTURE SURFACE PARAMETERS VERSUS FATIGUE LIFE}

The fish-eye was clearly observed on the fracture surface in the case of interior inclusion induced fracture. For such a fracture surface, inclusion size $b_{0}$, FGA size $b_{1}$ and depth of the inclusion $d$ measured from surface were defined as shown in Fig.5.

Correlations between each parameter for fracture surface and the fatigue life $N_{\mathrm{f}}$ are shown in Fig.6. Relationship of $d$ vs. $N_{\mathrm{f}}$ is shown in Fig.6(a). It is found that the depth of the inclusion does not relate to the fatigue life. Thus it seems that the fatigue period forming the fish-eye does not govern the total fatigue life in the case of interior inclusion induced fracture.

Relationship of $b_{0}$ vs. $N_{\mathrm{f}}$ is shown in Fig.6(b), in which experimental data were plotted separating into three groups of the applied stress. It is noted that the fatigue life tends to increase with an decrease of the inclusion size. Thus one can find that the inclusion size has a significant influence to the fatigue life in the case of interior inclusion induced fracture.

Figure6(c) indicates the relationship between FGA size $b_{1}$ and the fatigue life $N_{\mathrm{f}}$. Since a good correlation is observed, the FGA size also has a distinct influence to the fatigue life.

Here and there, the relationship between the stress amplitude at the inclusion $\sigma_{\mathrm{i}}$ and the fatigue life $N_{\mathrm{f}}$ is shown in Fig.7. One can find a significant correlation in this figure.

Based on the above analysis for the fracture surface, it was finally found that the long fatigue life was related to three parameters which are the stress amplitude at the inclusion, the inclusion size and the FGA size.

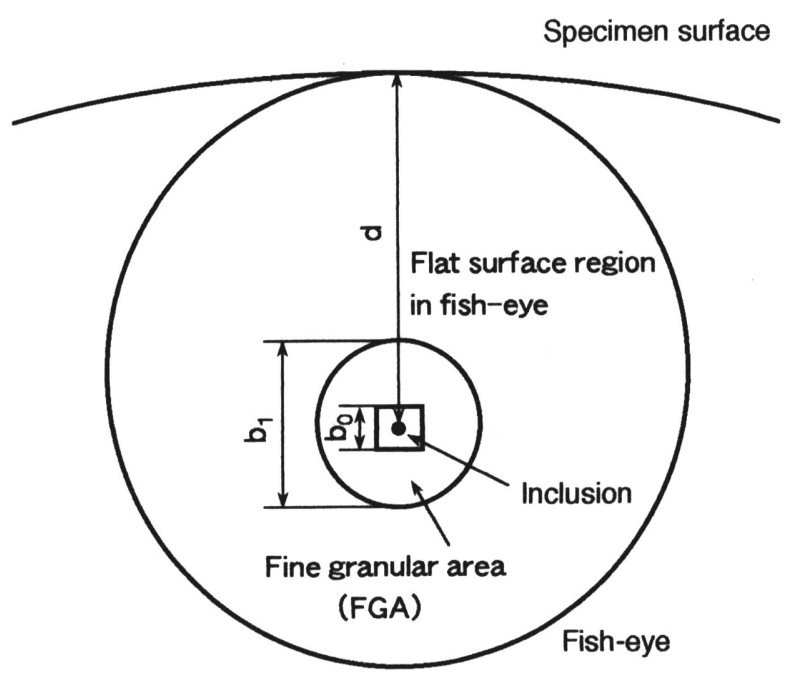

Fig.5. Definition of size and dimensions for fish-eye.
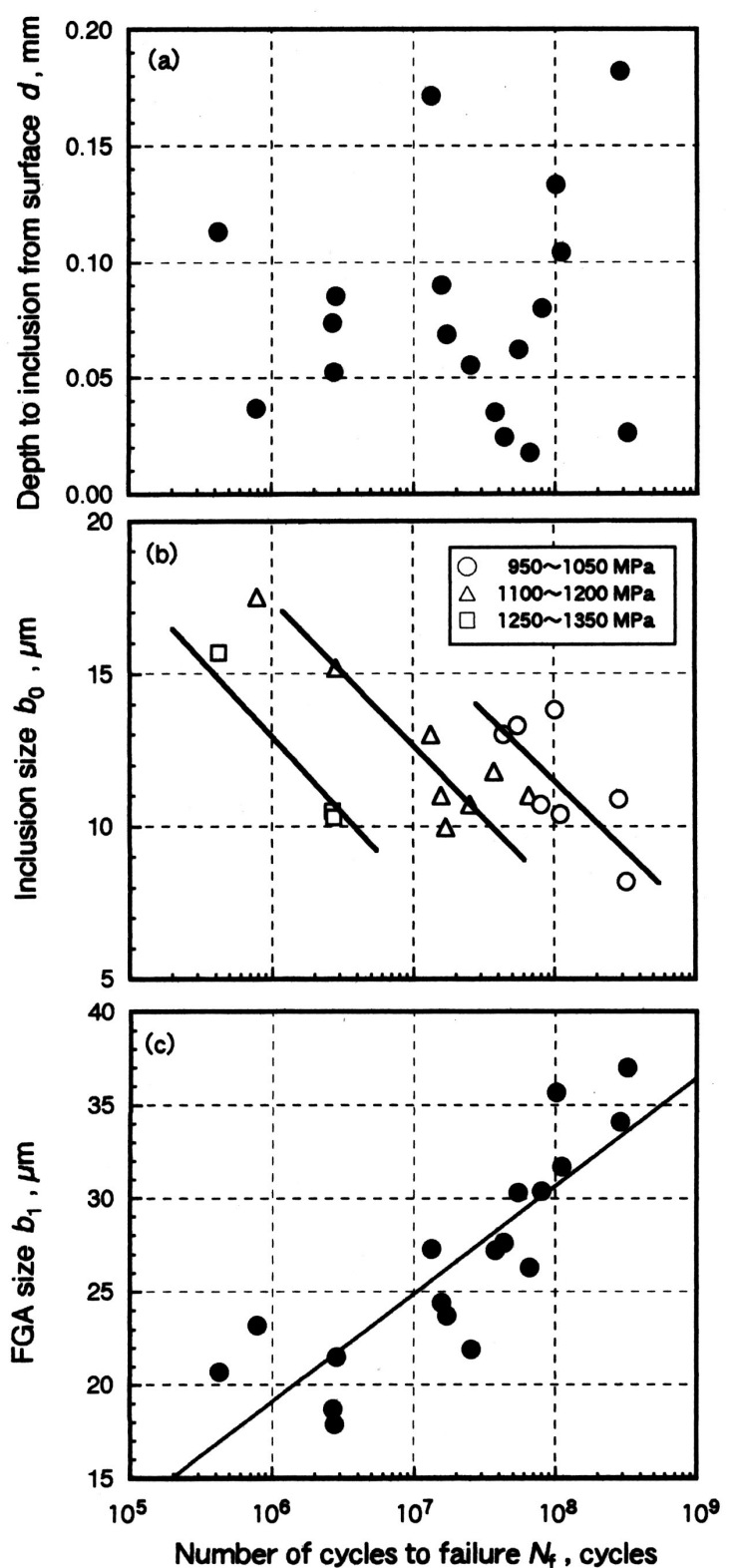

Fig.6. Correlations between fatigue life $N_{\mathrm{f}}$ and each one of parameters of $d, b_{0}$ and $b_{1}$

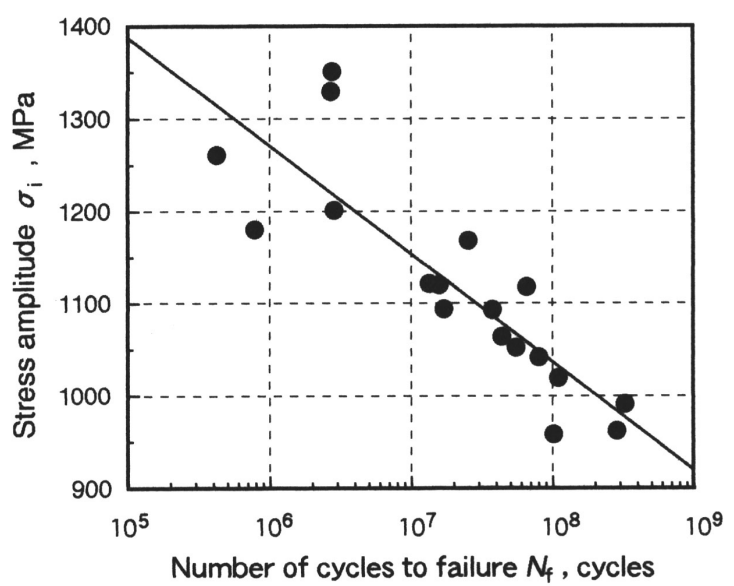

Fig.7. Relationship between stress amplitude at inclusion $Q_{1}$ and fatigue life $N_{\mathrm{f}}$. 


\section{FRACTURE MECHANICS ANALYSIS}

\subsection{Stress intensity factor}

Relationship between FGA size $b_{1}$ and the stress amplitude at the inclusion $\sigma_{\mathrm{i}}$ is plotted in Fig.8. FGA size $b_{1}$ tends to decrease with an increase of the stress amplitude at the inclusion $\sigma_{\mathrm{i}}$. FGA size $b_{1}$ is inversely proportional to the stress amplitude at the inclusion $\sigma_{i}$, and the coefficient of correlation is 0.968 . This fact suggests that one can discuss the FGA size from a viewpoint of fracture mechanics.

Stress intensity factor range at the front edge of FGA, $\Delta K_{\mathrm{FGA}}$, was calculated by using the following equation [10];

$$
\Delta K_{\mathrm{FGA}}=0.5 \sigma_{i} \sqrt{\pi b_{1}}
$$

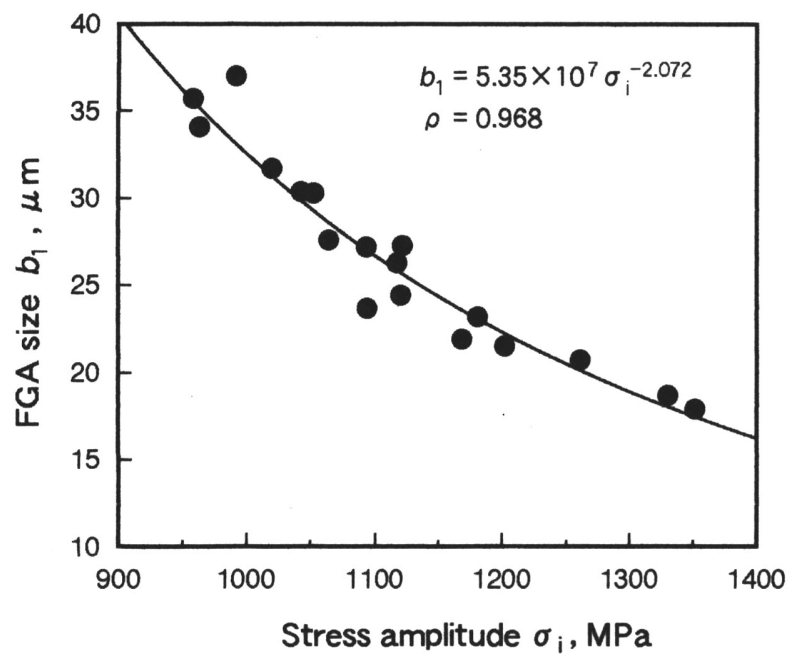

Fig.8. Relationship between FGA size $b_{1}$ and stress amplitude at the inclusion $\sigma_{\mathrm{i}}$.

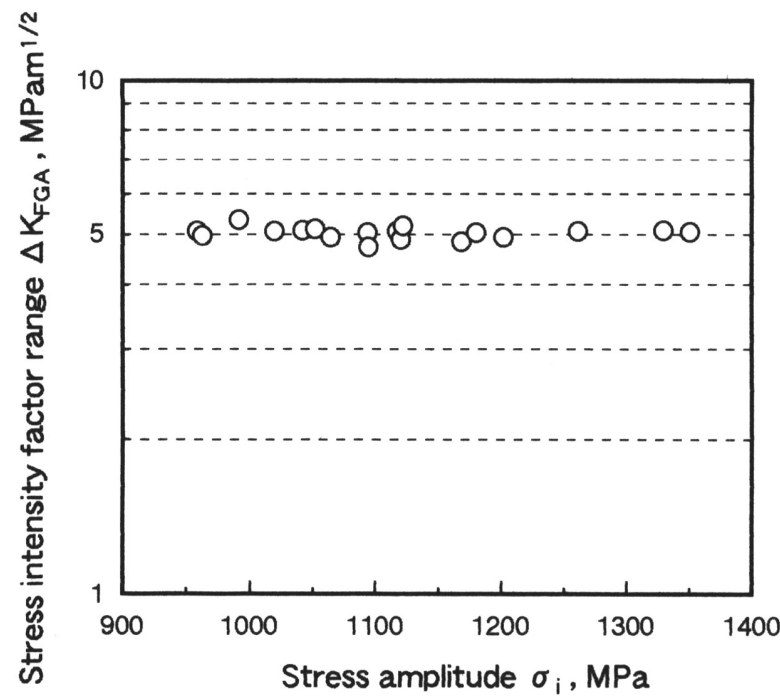

Fig.9. Analytical results of stress intensity factor range $\Delta K_{\mathrm{FGA}}$ obtained by individual stress amplitude at inclusion $\sigma_{\mathrm{i}}$.
Values of $\triangle K_{\mathrm{FGA}}$ thus calculated for FGA were plotted in Fig.9 as functions of the stress amplitude at inclusion $\sigma_{\mathrm{i}}$. In Fig.9, results of $\Delta K_{\mathrm{FGA}}$ keep almost constant regardless of $\sigma_{\mathrm{i}}$. This fact means that the stress intensity factor range at the FGA front provides the threshold value to cause the stable crack propagation, and its value is about $5 \mathrm{MPa} \cdot \mathrm{m}^{1 / 2}$. As reported in the other paper [11], threshold value of the fatigue crack propagation for this steel, $\Delta K_{\text {th }}$, is in a range of 4 to $6 \mathrm{MPa} \cdot \mathrm{m}^{1 / 2}$. Accordingly, if the value of $\triangle K_{\mathrm{FGA}}$ exceeds the critical value, the fatigue crack tends to propagate in accordance with the following equation well known as Paris' law;

$$
\mathrm{d} a / \mathrm{d} N=C(\Delta K)^{m}
$$

\section{2. Crack propagation analysis}

Based on the experimental evidence in the previous section, fatigue life can be divided into the following four stages;

1. Crack generation stage.

2. FGA formation stage.

3. Fish-eye formation stage.

4. Rapid crack propagation stage.

But the number of stress cycles in rapid crack propagation stage will be extremely less than ones in the other stages. If we neglect this short stage, the fatigue life $N_{\mathrm{f}}$ is given by the following expression;

$$
N_{\mathrm{f}}=N_{0}+N_{\mathrm{FGA}}+N_{\text {fish-eye }}
$$

where $N_{0}, N_{\mathrm{FGA}}$ and $N_{\text {fish-eye }}$ indicate stress cycles at the respective stages of 1,2 and 3 .

As reported in the other paper [12], the number of cycles in the fish-eye formation stage $N_{\text {fish-eye }}$ is expected to occupy a small portion of fatigue life rather than the crack generation stage and the FGA formation stage. Therefore, the fatigue life $N_{\mathrm{f}}$ is almost the sum of $N_{0}$ and $N_{\text {FGA }}$.

If the fatigue crack propagation behavior inside of the FGA is governed by the Paris' law as shown in Eq.(2), $N_{\mathrm{FGA}}$ is defined by the number of cycles over which a crack grows from an initial length $b_{0} / 2$ to a critical length $b_{1} / 2$ in the FGA formation stage. That is, $N_{\mathrm{FGA}}$ is obtained by the partial integration of Eq.(2) from $b_{0} / 2$ to $b_{1} / 2$ as follows;

$$
N_{\mathrm{FGA}}=\int_{b_{0} / 2}^{b_{1} / 2} \frac{\mathrm{d} a}{C \Delta K^{m}}
$$

Thus we have the following result;

$$
N_{\mathrm{FGA}}=\frac{2\left({\frac{b_{1}}{2}}^{1-m / 2}-{\frac{b_{0}}{2}}^{1-m / 2}\right)}{C(2-m)\left(0.5 \sigma_{\mathrm{i}} \sqrt{2 \pi}\right)^{m}}
$$

Using $\Delta K_{\mathrm{FGA}}$ of Eq.(1), Eq.(5) can be rewritten as follows;

$$
N_{\mathrm{FGA}}=B \frac{\left(b_{1}{ }^{1-m / 2} b_{1}{ }^{m / 2}-b_{0}{ }^{1-m / 2} b_{1}{ }^{m / 2}\right)}{\Delta K_{\mathrm{FGA}}{ }^{m}}
$$




$$
\begin{aligned}
& =\frac{B}{\Delta K_{\mathrm{FGA}}^{m}}\left(b_{1}-b_{0}{ }^{1-m / 2} b_{1}{ }^{m / 2}\right) \\
& =\frac{B b_{1}}{\Delta K_{\mathrm{FGA}} m}\left\{1-\left(\frac{b_{0}}{b_{1}}\right)^{1-m / 2}\right\}
\end{aligned}
$$

where $B$ is the constant part in Eq.(5).

Furthermore, through Eq.(1), Eq.(6) can be reduced as follows;

$$
N_{\mathrm{FGA}}=B^{\prime} \Delta K_{\mathrm{FGA}}{ }^{2-m} \sigma_{\mathrm{i}}{ }^{-2}\left\{1-\left(\frac{b_{0}}{b_{1}}\right)^{1-m / 2}\right\}
$$

where

$$
B^{\prime}=\frac{4}{C(2-m) \pi}
$$

Since $\triangle K_{\mathrm{FGA}}$ takes the constant value, the FGA formation life $N_{\mathrm{FGA}}$ is a function of the stress amplitude at the inclusion $\sigma_{\mathrm{i}}$ and the size ratio of $b_{0} / b_{1}$. Thus, we have the following expression;

$$
N_{\mathrm{FGA}}=g\left(\sigma_{\mathrm{i}}\right)-g\left(\sigma_{\mathrm{i}}\right)\left(\frac{b_{0}}{b_{1}}\right)^{1-m / 2}
$$

where

$$
g\left(\sigma_{\mathrm{i}}\right)=B^{\prime} \Delta K_{\mathrm{FGA}}{ }^{2-m} \sigma_{\mathrm{i}}{ }^{-2}
$$

On the other hand, the experimental data were plotted in Fig. 10 as the relationship between the size ratio of $b_{0} / b_{1}$ and the fatigue life. The marks are classified into three classes of the stress amplitude at the inclusion similar to Fig.6(b). In Fig.10, the fatigue life in each class thus classified relates to the size ratio of $b_{0} / b_{1}$.

Considering that the fatigue life $N_{\mathrm{f}}$ is almost the sum of $N_{0}$ and $N_{\mathrm{FGA}}$, regression curves in Fig.10 give us the following equation;

$$
N_{\mathrm{FGA}}=-N_{0}+G\left(\sigma_{\mathrm{i}}\right)\left(\frac{b_{0}}{b_{1}}\right)^{h\left(\sigma_{\mathrm{i}}\right)}
$$

where $G\left(\sigma_{\mathrm{i}}\right)$ and $h\left(\sigma_{\mathrm{i}}\right)$ are the regression coefficient part and the regression index, respectively, of the regression curves in Fig.10. Both variables are expressed as functions of $\sigma_{\mathrm{i}}$, because these values change depending on the stress amplitude at the inclusion.

Based on the analogy of Eqs.(9) and (11), we can put;

$$
\left\{\begin{array}{l}
g\left(\sigma_{\mathrm{i}}\right)=-N_{0} \\
g\left(\sigma_{\mathrm{i}}\right)=-G\left(\sigma_{\mathrm{i}}\right)
\end{array}\right.
$$

that is,

$$
N_{0}=G\left(\sigma_{\mathrm{i}}\right)
$$

Thus, it was found that the number of cycles in the crack generation stage depends on the stress amplitude at the inclusion, and it can be estimated from the regression curve such as shown in Fig. 10.

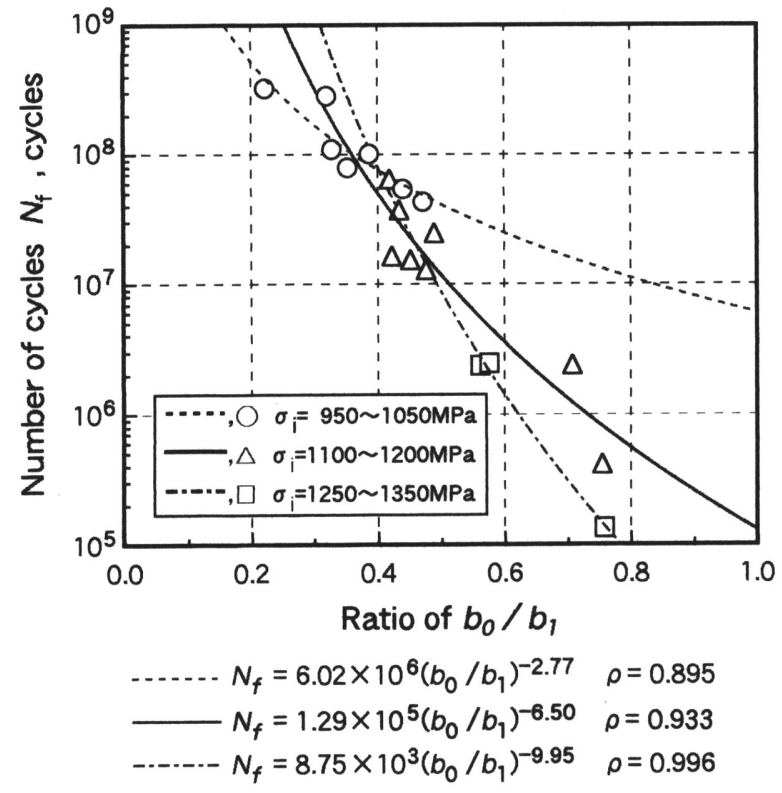

Fig.10. Relationship between fatigue life $N_{\mathrm{f}}$ and size ratio of $b_{0} / b_{1}$.

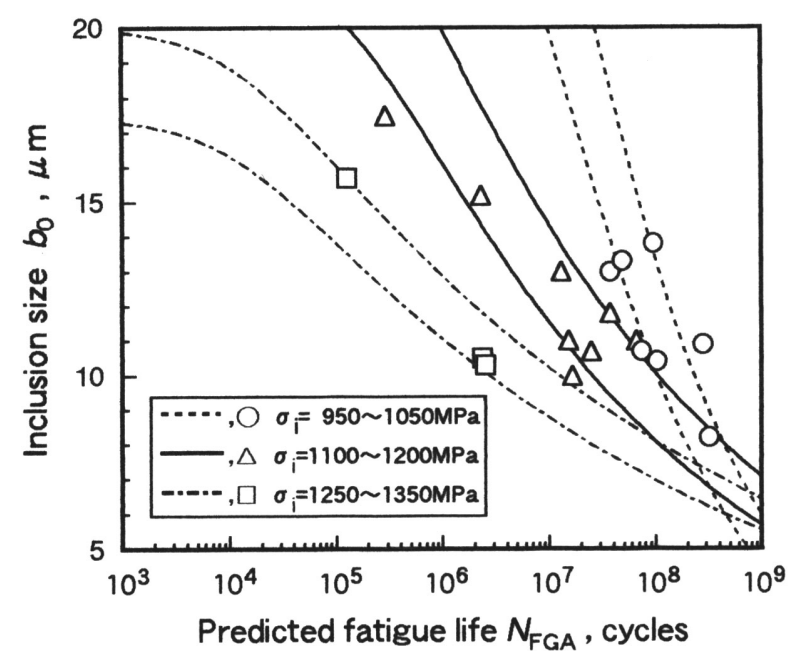

Fig.11. Analytical results and experimental results of predicted fatigue life $N_{\mathrm{f}}$.

\section{3. Parameters of crack propagation law}

When the theoretical Eq.(9) is compared with the experimental Eq.(11), both indexes have to be equal. So, the following equation is obtained;

$$
m=2\left\{1-h\left(\sigma_{\mathrm{i}}\right)\right\}
$$

Eq.(7) can be rewritten as follows;

$$
B^{\prime}=\frac{N_{\mathrm{FGA}} \sigma_{\mathrm{i}}^{2} \Delta K_{\mathrm{FGA}}^{m-2}}{1-\left(\frac{b_{0}}{b_{1}}\right)^{1-m / 2}}
$$

Substituting Eq.(8) into Eq.(15), we have the following equation; 


$$
C=\frac{4\left\{1-\left(\frac{b_{0}}{b_{1}}\right)^{1-m / 2}\right\}}{(2-m) \pi N_{\mathrm{FGA}} \sigma_{\mathrm{i}}^{2} \Delta K_{\mathrm{FGA}}^{m-2}}
$$

Making reference to some experimental results for the crack growth law, one can calculate the parameters of $m$ and $C$, respectively.

\section{PREDICTION OF CRACK PROPAGATION}

The FGA forming life can be calculated by Equation (4) analytically. From a viewpoint of fatigue life prediction, FGA forming life was estimated as a function of the stress amplitude at inclusion and the inclusion size. Thus we can conclude that FGA forming life is expected to occupy more than $90 \%$ of fatigue life.

Relationship between the inclusion size $b_{0}$ and predicted fatigue life $N_{\mathrm{FGA}}$ as analytical results is shown in Fig.11 together with the experimental results. The experimental results are within the scatter bands predicted by the present procedure. Thus, the predicted life is well corresponding to the experimental results. Therefore the method of fatigue life prediction based on fracture mechanics in this paper is useful for the engineering applications.

Figure 11 indicates that the predominant factor to expand the fatigue life of this steel is smallness of the inclusion size. This fact means that efforts to reduce the inclusion size are highly to expand the fatigue life of this steel.

\section{CONCLUSIONS}

(1) The factors governed the fatigue life of interior inclusion induced fracture with fish-eye were stress amplitude at the inclusion, inclusion size and fine granular area (FGA) size. These factors can be connected to the parameters in the formula of Paris' law
(2) FGA was observed in a vicinity around the inclusion at center of the fish-eye. Stress intensity factor range $\triangle K_{\mathrm{FGA}}$ which was calculated by FGA size and stress amplitude at inclusion was almost constant of $5 \mathrm{MPa} \cdot \mathrm{m}^{1 / 2}$.

(3) FGA formation life can be evaluated form a viewpoint of fracture mechanics.

(4) It was found that the FGA forming life occupied more than $90 \%$ of the total fatigue life, except for the case of extremely large inclusion size. It was another finding that effective factor to expand the fatigue life was smallness of the inclusion size.

\section{REFERENCES}

1. T. Naito, H. Ueda and M. Kikuchi, Metal. Trans., 15A, (1984), p. 1431.

2. K. Asami and M. Hironaga, J. Soc. Mater. Sci., Japan, 43 (1994), p. 12 (in Japanese).

3. K. Kanazawa and S. Nishijima, J. Soc. Mater. Sci., Japan, 46 (1997), p. 1396 (in Japanese).

4. C.Bathias, Fatigue Fract. Engng. Mater. Struct., 22 (1999), p. 559.

5. T. Sakai, Y. Sato and N. Oguma, Trans JSME, 67A (2001), P.1980 (in Japanese).

6. H. Mughrabi, Harteri-Technische Mitteilunger, 56 (2001), p.300.

7. Y. Nadot and T. Billaudeau, Proc. Int. Conf. on Fatigue in the Very High Cycle Regime, (2001), p.303.

8. T. Sakai, Y. Sato and N. Oguma, Fract. Engng. Mater. Struct., 25 (2002), p. 765.

9. T. Sakai et al., J. Soc. Mater. Sci., Japan, 49 (2000), p. 779 (in Japanese).

10. Y. Murakami, S. Kodama and S. Onuma, Trans JSME, 54A (1988) p.688 (in Japanese).

11. K. Shiozawa, Lu L. T. and S. Ishihara, J. Soc. Mater. Sci., Japan, 48 (1999), p. 1095 (in Japanese).

12. N. Oguma and T. Sakai, J. Soc. Mater. Sci., Japan, 50 (2001), p. 516 (in Japanese). 